Article

\title{
From the Lab to the Field: Combined Application of Plant-Growth-Promoting Bacteria for Mitigation of Salinity Stress in Melon Plants
}

\author{
Vinoj Gopalakrishnan, Saul Burdman, Edouard Jurkevitch and Yael Helman * (D)
}

check for updates

Citation: Gopalakrishnan, V.;

Burdman, S.; Jurkevitch, E.; Helman, Y. From the Lab to the Field:

Combined Application of

Plant-Growth-Promoting Bacteria for

Mitigation of Salinity Stress in Melon

Plants. Agronomy 2022, 12, 408.

https://doi.org/10.3390/

agronomy12020408

Academic Editor: Munagala S. Reddy

Received: 3 January 2022

Accepted: 3 February 2022

Published: 6 February 2022

Publisher's Note: MDPI stays neutral with regard to jurisdictional claims in published maps and institutional affiliations.

Copyright: (C) 2022 by the authors. Licensee MDPI, Basel, Switzerland. This article is an open access article distributed under the terms and conditions of the Creative Commons Attribution (CC BY) license (https:// creativecommons.org/licenses/by/ $4.0 /)$.
Department of Plant Pathology and Microbiology, Institute of Environmental Sciences, The Robert H. Smith Faculty of Agriculture, Food and Environment, The Hebrew University of Jerusalem, Rehovot 7610001, Israel; vinojvino@gmail.com (V.G.); saul.burdman@mail.huji.ac.il (S.B.); edouard.jurkevitch@mail.huji.ac.il (E.J.)

* Correspondence: yael.helman@mail.huji.ac.il

\begin{abstract}
Soil salinization is a major and increasing problem adversely impacting plant growth and crop production. Accordingly, coping with this problem has become a central topic in agriculture. In this study, we address this issue by evaluating the potential effectiveness of two bacterial species, Azospirillum brasilense and Paenibacillus dendritiformis, in enhancing growth and yield of melon and tomato plants under salinity stress. In vitro laboratory experiments indicated that these bacteria can efficiently colonize plant roots, and increase root length (25-33\%) and root biomass (46-210\%) of three melon plant varieties under saline stress. Similarly, greenhouse experiments showed that these bacteria significantly induced root (78-102\%) and shoot weights (37-57\%) of the three melon varieties irrigated with saline water. Tomato plants grown under the same conditions did not exhibit growth deficiency upon exposure to the saline stress and their growth was not enhanced in response to bacterial inoculation. Interestingly, saline-stressed melon plants inoculated with $P$. dendritiformis and $A$. brasilense exhibited lower total antioxidant activity compared to un-inoculated plants ( $80 \%$ vs. $60 \%$ of DPPH radical scavenging activity, respectively), suggesting that the inoculated plants experienced lower stress levels. These positive effects were further manifested by an increase of $16 \%$ in the crop yield of melon plants grown in the field under standard agricultural fertilization practices, but irrigated with saline water. Overall, these results demonstrate the beneficial effects of two plant-growth-promoting rhizobacteria, which can significantly alleviate the negative outcome of salt stress.
\end{abstract}

Keywords: soil salinity; PGPR; Paenibacillus; Azospirillum; melon; tomato; wheat

\section{Introduction}

Soil salinity is one of the major abiotic stresses reducing plant growth and crop production worldwide [1-3]. It is caused by excessive accumulation of water-soluble salts, resulting from both natural and human-induced processes. The natural processes contributing to soil salinization include, among others, parent rock weathering, dispersion of saline dust and high evaporation vs. precipitation events [4]. Anthropogenic causes include inappropriate application of fertilizers, use of low-quality water in irrigation and prevention of leaching due to inadequate drainage [5]. High salt concentrations in the soil lead to various detrimental effects on plant physiology, ranging from the disturbance of intracellular ionic homeostasis and reduced nutrient mobilization to plant hormone imbalance and the altered development of reproductive structures [6-8]. Furthermore, high soil salinity can drastically affect the microbial population in the rhizosphere, which in turn impacts plant productivity [9-11]. According to the Food and Agricultural Organization (FAO), a significant portion of the Earth's total land mass will be converted into saline soil by 2050 [12], posing a significant worldwide threat to crop production and hence 
to food security. Accordingly, coping with this problem has become an important issue in agriculture.

One of the main ways to cope with saline soils is by active removal of salts $[13,14]$. However, this process requires large quantities of high quality irrigation water, as well as effective soil drainage, which are typically missing in areas of saline soils [12]. An attractive approach to alleviate salinity and other abiotic stresses involves the manipulation of the rhizosphere microbial community in favor of plant-growth-promoting rhizobacteria (PGPRs) [15-18]. The positive effects of PGPRs on plant growth involve a variety of direct or indirect mechanisms. Direct mechanisms include the provision of nutrients in a form available to the plant, degradation of environmental pollutants and production of plant hormones, whereas indirect mechanisms include induced systemic resistance (ISR) and control of phytopathogens by competing for resources such as iron, amino acids and sugars, as well as by producing antibiotics or lytic enzymes [19-24]. Despite their potential as lowinput environmentally friendly agents for plant protection, the application of PGPRs in the field is limited. This is often attributed to poor rhizosphere competence, which results from ineffective root colonization combined with the difficulty to survive and proliferate along growing plant roots in the presence of the indigenous population of microorganisms [25].

Combined application of PGPRs with demonstrated colonization and survival abilities as well as plant-growth-promotion mechanisms might broaden the overall compatibility of the inoculant and offer a more consistent success in the field. This approach has gained increased interest in recent years and various combinations of microorganisms have been examined as potential plant-growth-promoting and biocontrol agents. For example, commercial inoculants composed of Azospirillum brasilense and Pseudomonas fluorescens strains have been developed for plant-growth promotion of cereals [26]. Azospirillum brasilense has also been shown to improve the symbioses of a variety of legume-rhizobia systems, including under field conditions [27-30]. Similarly, co-inoculation of Bacillus spp. strains with Bradyrhizobium japonicum substantially increased total biomass and grain yield of soybean [31], and co-inoculation of Paenibacillus mucilaginosus with Rhizobium spp. increased the tolerance of alfalfa to copper stress and increased the soil nutrient content [32].

Several Paenibacillus spp. and A. brasilense strains are known to display strong associations with plants roots, promoting plant growth under various agro-ecological conditions in different crops [26,33-36]. A number of mechanisms have been shown to be at play, including nitrogen fixation, phosphate solubilization, secretion of phytohormones, and the induction of systemic resistance [34,37-39]. In this study, we examined the potential efficiency of $A$. brasilense and Paenibacillus dendritiformis, as single or dual inoculants, to promote growth of melon and tomato plants and alleviate salt stress in greenhouse and field conditions. While the plant-growth-promoting effects of $A$. brasilense have been widely reported in cereals, forage plants and legumes [26,35], little is known about the interaction of this bacterium with plants from the Cucurbitaceae and Solanaceae families [40,41]. Genome analyses of $P$. dendritiformis indicated that its genome encodes various genes required for competition over resources (e.g., iron, amino acids, and sugar transporters) and for producing offensive (antibiotics and lytic enzymes), as well as defensive (resistance to antibiotics and other toxins) compounds [42]. These attributes and the facts that strains of this species were shown to promote growth of potato plants [43] and Amaranthus polygonoides L. sprouts [44], as well as reduce disease symptoms caused by Colletotrichum truncatum in chilli (Capsicum annuum) [45], suggested that it could serve as a suitable coinoculant with $A$. brasilense. Here, we show that both $A$. brasilense and $P$. dendritiformis can alleviate salt stress and act as efficient PGPRs of melon crops.

\section{Materials and Methods}

\subsection{Bacterial Strains, Growth Conditions and Plant Material}

Azospirillum brasilense strain Sp7 was isolated from Digitaria decumbens roots in Rio de Janeiro, Brazil [46], and is available in the S. Burdman strain collection (kindly provided by Y. Okon). Paenibacillus dendritiformis strain T (Bacillus Genetic Stock Center \#30A1) [47] 
was kindly provided by the late E. Ben-Jacob. Escherichia coli SM10 [48] is available in the Y. Helman strain collection. Bacteria were grown in Lysogenic broth (LB) (Difco Laboratories, Detroit, MI, USA) or LB $1.5 \%$ agar (LA) plates for $24 \mathrm{~h}$ at $28{ }^{\circ} \mathrm{C}$. For plant inoculation the cells were harvested from the agar plate and resuspended with phosphate buffer-saline solution (PBS; $10 \mathrm{mM}$ sodium phosphate, $2.7 \mathrm{mM}$ potassium chloride, $1.8 \mathrm{mM}$ potassium phosphate, $137 \mathrm{mM}$ sodium chloride; $\mathrm{pH} 7.4$ ) to a final concentration of $10^{8}$ colony forming units (CFU) $\mathrm{mL}^{-1}$ as adjusted by optical density at $600 \mathrm{~nm}\left(\mathrm{OD}_{600}\right)$ of 0.2 and verified by serial dilution plating. Bacterial suspensions containing A. brasilense and $P$. dendritiformis were prepared by mixing equal volumes of suspensions of both strains. Plant material used in this study included melon (Cucumis melo) cultivars (cvs.) Ofir (Zeraim Gedera, Revadim, Israel), AN-305 (Origene Seeds, Givat Brenner, Israel) and Raymond (Hazera Genetics, Brurim Farm, Israel), tomato (Solanum lycopersicum) cv. M82 (Hazera Genetics, Israel), and wheat (Triticum aestivum) cv. Bar Nir (Negev Seeds, Kibbutz Shoval, Israel).

\subsection{Assessment of Bacterial Root Colonization}

Prior to bacterial inoculation, seeds were surface-sterilized by soaking in $70 \%$ ethanol for $1 \mathrm{~min}$, followed by soaking in 1\% sodium hypochlorite for $1 \mathrm{~min}$. The seeds were then rinsed five times with sterile distilled water and dried on filter paper. To assess the colonization ability of the bacterial strains on melon, tomato and wheat roots, seeds were germinated on germination papers using the "cigar roll" method [49]. Briefly, ten uniform-size seeds were placed on a moist germination paper $(25 \mathrm{~cm} \times 38 \mathrm{~cm}$; Hoffman Manufacturing, Inc., Corvallis, OR, USA). The paper was covered with another sheet of moist germination paper rolled to a final diameter of $3 \mathrm{~cm}$. The bases of the rolls were placed in $1 \mathrm{~L}$ chemical beakers containing a water solution and they were kept in a darkened growth chamber at a constant temperature of $25^{\circ} \mathrm{C}$ for seven days. Then, roots from the emerging seedlings were incubated in $10^{8} \mathrm{CFU} \mathrm{mL}{ }^{-1}$ suspensions of each bacterial strain at $25^{\circ} \mathrm{C}$ for 2 or $24 \mathrm{~h}$. After incubation, the roots were gently washed twice with sterilized PBS, dried on filter paper and weighed. The roots were then vortexed for $30 \mathrm{~s}$ in $1 \mathrm{~mL}$ of fresh PBS in 1.5-mL tubes followed by transfer to $1 \mathrm{~mL}$ fresh PBS and homogenized using an RZR 2-64 homogenizer (Heidolph, Schwabach, Germany). Both suspensions resulting from vortexed and homogenized roots were serially diluted and plated on LA plates for bacterial quantification. Plates were incubated at $28^{\circ} \mathrm{C}$ for $48 \mathrm{~h}$, after which colonies were counted to measure colonization ( $\mathrm{CFU} \mathrm{g}{ }^{-1}$ root).

\subsection{Seedling Growth in Germination Paper}

Seeds of melon and tomato were surface-sterilized as described above and incubated for $30 \mathrm{~min}$ in suspensions containing $10^{8} \mathrm{CFU} \mathrm{mL} \mathrm{m}^{-1}$ of A. brasilense Sp7 and P. dendritiformis $\mathrm{T}$, separately or in combination of both strains. Seedlings were grown on germination papers using the "cigar roll" method as described above. The chemical beakers contained either water or $50 \mathrm{mM} \mathrm{NaCl}$ solution. Seedlings were grown in a dark growth chamber at $25^{\circ} \mathrm{C}$. After 10 days, plants were collected and the following parameters were measured: root length, root weight, number of lateral roots and number of lateral roots equal or larger than $2 \mathrm{~cm}$.

\subsection{Greenhouse Experiments}

All greenhouse experiments were carried out on campus in the I-Core greenhouse equipped with a desert cooler (minimum-maximum temperature: $14-36^{\circ} \mathrm{C}$ ). Preliminary experiments were carried out with melon and tomato plants to assess their susceptibility to saline stress. Experiments involving bacterial inoculation were performed with melon and tomato varieties described above. Seeds were surface-sterilized as described above and germinated in a vermiculite-filled tray that was irrigated with water. Then, 12-day-old seedlings were transferred to $2 \mathrm{~L}$ plastic pots filled with sand. The plants were irrigated with a standard nutrient solution (NPK fertilization solution; $1.8 \mathrm{~g} \mathrm{~L}^{-1} \mathrm{~N}: \mathrm{P}_{2} \mathrm{O}_{5}: \mathrm{K}_{2} \mathrm{O}$ (5:3:8); Haifa 
Chemicals Ltd., Haifa, Israel), carrying $\mathrm{NaCl}$ at an EC of $\sim 3.5 \mathrm{dS} \mathrm{m}^{-1}$, through an automatic drip irrigation system, three times per day. Bacterial inoculation was performed twice, the first time at sowing, and the second time when seedlings were transplanted to the pots. In both cases, each seed/plant was inoculated with $5 \mathrm{~mL}$ of bacterial suspensions of either $10^{8} \mathrm{CFU} \mathrm{mL} \mathrm{m}^{-1}$ of $A$. brasilense Sp7, P. dendritiformis $\mathrm{T}$ or a mixed suspension containing both bacterial strains at the same concentration as in individual inoculation. Controls were non-inoculated plants. The plants were grown for 45 additional days, after which root and shoot weights were determined. All greenhouse experiments were organized in a completely randomized design with 20 replicates (plants) per treatment.

\subsection{Measurements of Total Antioxidant Enzyme Activity}

Antioxidant activity was measured using the 2,2-diphenyl-1-picrylhydrazyl (DPPH) radical scavenging assay described by Zhou et al. (2018) [50]. Forty-five-day-old melon plants (cv. Ofir) grown in the greenhouse as described above were used for this analysis. Briefly, fresh root or leaf tissue $(1 \mathrm{~g})$ was homogenized in an $80 \%$ methanol $(v / v)$ solution using tissue lyser II (Qiagen, Hilden, Germany). Samples were then centrifuged at $13,000 \times g$ for $20 \mathrm{~min}$ at $4{ }^{\circ} \mathrm{C}$. The supernatant $(2 \mathrm{~mL})$ was mixed with $1 \mathrm{~mL}$ of $0.3 \mathrm{mM} \mathrm{DPPH}$ solution and incubated in the dark at $25^{\circ} \mathrm{C}$ for $30 \mathrm{~min}$. Absorbance of the solution was then measured at $517 \mathrm{~nm}$. The test was carried out with four replicates per treatment. Percentage of radical scavenging activity was calculated according to the following formula:

$\mathrm{DPPH}$ radical scavenging activity $\%=100-100 \times\left[\left(\mathrm{Ab}_{\text {sample }}-\mathrm{Ab}_{\text {blank }}\right) / \mathrm{Ab}_{\text {control }}\right]$

DPPH solution in $80 \%$ methanol $(v / v)$ served as control. The methanol solution with the corresponding plant extracts was used as blank.

\subsection{Field Experiment}

A field experiment with melon cv. AN-305 was performed at the Zohar Central and Northern Arava-Tamar Agricultural Station (Ein Tamar, Israel) in a sandy soil (76-84\% sand, $7-14 \%$ silt, $11-12 \%$ clay), using plantlets produced by Hishtil Nurseries (Nehalim, Israel). The experiment included four treatments: inoculation with A. brasilense Sp7 or $P$. dendritiformis $\mathrm{T}$, inoculation with both strains, and non-inoculated controls. Bacterial treatments were applied as described for greenhouse experiments, with a first dose given at sowing in the nursery, and a second dose being applied just before transplanting the plantlets into the field (14 days after sowing). The plants were planted in four rows (200 plants per row), at intervals of $0.4 \mathrm{~m}$. The experiment was set up as a randomized design, including twenty replicates (plots) per treatment, each plot containing 10 plants. Plants were covered with an insect screen until 25 days after planting to avoid virus damage. The plants were irrigated with local, saline irrigation $\left(E C \sim 3.5 \mathrm{ds} \mathrm{m}^{-1}\right)$, with an application of standard fertilization optimized for commercial cultivation of the crop. The experiment was finalized 120 days after transplanting. The fruits of all the plots were collected, counted and weighed.

\subsection{Fluorescence in Situ Hybridization Experiments}

Fluorescence in situ hybridization (FISH) analyses were carried out on 24-day-old melon plants (cv. AN-305) grown in sand pots and inoculated with A. brasilense Sp7, P. dendritiformis $\mathrm{T}$ or with both strains as described for greenhouse experiments. Probe design for A. brasilense and P. dendritiformis was performed with the PROBE Design tool of the ARB software package [51]. Oligonucleotide probes were modified at the $5^{\prime}$-end with the fluorescent fluorophores Cy3 for the P. dendritiformis probe (5'-GGATAGGCGATTTCCTCGCA-3'; 16S rRNA position 1149-1169) and Cy5 for the A. brasilense probe (5'-CCACCTTCGGGTAAAGCCA-3'; $16 \mathrm{~S}$ rRNA position 1176-1196). Prior to hybridization, root samples (5 $\mathrm{cm}$ in length) were fixed in $35 \%$ formaldehyde for $24 \mathrm{~h}$ at $4{ }^{\circ} \mathrm{C}$ followed by dehydration in increasing concentrations of ethanol (10 min in each of the following concentrations: $50 \%, 70 \%, 85 \%$, and $100 \%$ ). Hybridization was performed at $42{ }^{\circ} \mathrm{C}$ for $4 \mathrm{~h}$ using hybridization buffer containing $0.9 \mathrm{M}$ 
$\mathrm{NaCl}, 20 \mathrm{mM}$ Tris $\mathrm{HCl}$ (pH 7.2), $5 \mathrm{mM}$ EDTA, 0.001\% SDS and 35\% formamide. The specific probes were added to a final concentration of $30 \%(v / v)$ for each probe. Following incubation, the hybridization solution was drained and replaced with pre-warmed $80 \mathrm{mM}$ washing buffer containing $10 \mathrm{M} \mathrm{NaCl}, 20 \mathrm{mM}$ Tris $\mathrm{HCl}$ (pH 7.2), 10 mM EDTA. Samples were visualized using a Zeiss LSM-510 confocal laser-scanning microscope (Carl Zeiss, Jena, Germany) with two-helium neon lasers for excitation of Cy3 and Cy5 at 543 and $633 \mathrm{~nm}$, respectively. Samples were observed under water immersion using a 63X objective.

\subsection{Statistical Analyses}

Data were analyzed by one-way analysis of variance (ANOVA) and the Tukey post hoc test using the JMP software (SAS Institute Inc., Cary, NC, USA).

\section{Results}

3.1. Azospirillum brasilense Sp7 and Paenibacillus dendritiformis T efficiently Colonize Melon and Tomato Roots

An important trait of efficient PGPRs is their ability to colonize the plant's roots. We therefore examined the root colonization ability of A. brasilense Sp7 and P. dendritiformis $\mathrm{T}$ in melon and tomato plants. Colonization efficiency was compared to that of Escherichia coli, which is not a natural root colonizer and thus could serve as a non-efficient colonization control. Wheat roots were used as a positive control for bacterial colonization since A. brasilense strains are known to effectively colonize the roots of this and other cereals [52]. Bacterial numbers (normalized to CFU per gram root) were determined following mechanical detachment of bacterial cells from the roots by two sequential steps, involving vortex followed by root homogenization. Bacterial colonization was measured 2 and $24 \mathrm{~h}$ after inoculation. These times were selected based on the biphasic model for attachment of A. brasilense and other bacteria to plant roots, by which root colonization comprises a fast, weak and reversible stage that occurs within $2 \mathrm{~h}$, followed by a second step that occurs in the following hours and is characterized by firm and irreversible anchoring [53-55].

Azospirillum brasilense Sp7 and P. dendritiformis T successfully colonized the roots of the tested varieties of melon, tomato and wheat, with colonization levels varying from $\sim 10^{5}-10^{6} \mathrm{CFU} \mathrm{g}{ }^{-1}$ root after $2 \mathrm{~h}$ of incubation to $\sim 10^{7} \mathrm{CFU} \mathrm{g}{ }^{-1}$ root after $24 \mathrm{~h}$. With that said, it seems that colonization abilities of both strains were slightly more efficient in melon and wheat than in tomato roots, particularly at the earliest sampling time (Figure 1). As expected, colonization ability of E. coli cells was poor, reaching levels of only $10^{4}$ to $10^{5}$ $\mathrm{CFU} \mathrm{g}{ }^{-1}$ in both melon and tomato roots. These results indicate that both $A$. brasilense Sp7 and P. dendritiformis T possess the ability to efficiently colonize the roots of melon and tomato roots. Moreover, the levels of root colonization in these plants were comparable to those observed for wheat, a known plant-growth-promotion target of $A$. brasilense [52].

Several studies have shown that $P$. dendritiformis possesses antimicrobial activities $[44,56,57]$. However, when $P$. dendritiformis $\mathrm{T}$ was plated on agar media together with $A$. brasilense Sp7, no growth inhibition of the latter was observed (Figure S1a). Moreover, preliminary fluorescence in situ hybridization (FISH) analyses using specific probes designed against P. dendritiformis and A. brasilense could detect co-aggregates of the bacterial species on roots of 24 day-old-melon plants grown in sand pots (Figure S1b). Overall, these results support the idea that these two bacterial strains can be used in co-inoculation application. 
(a)

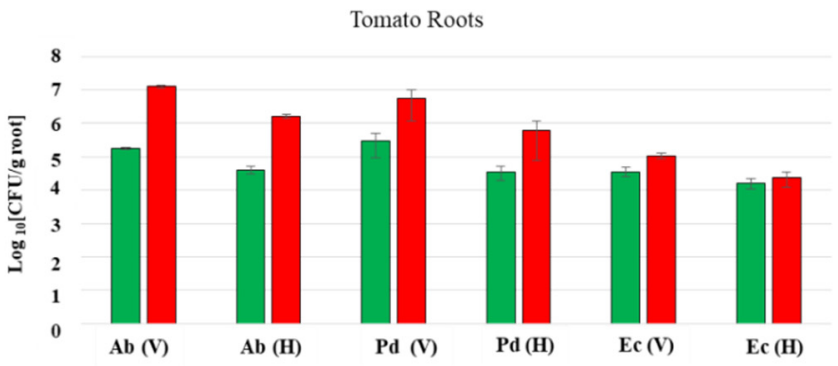

(b)

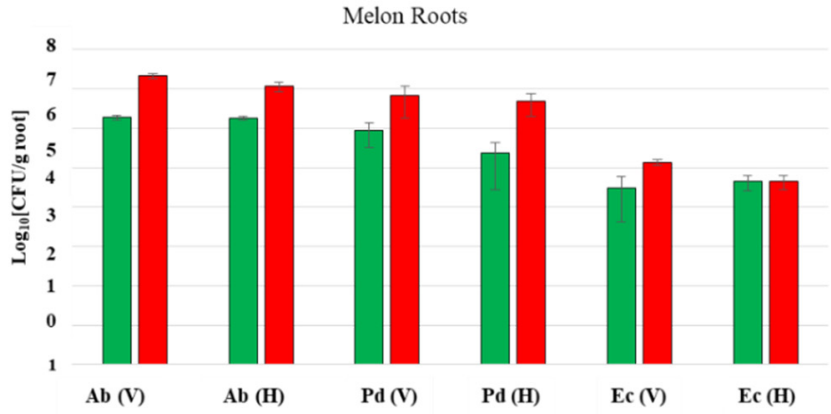

(c)

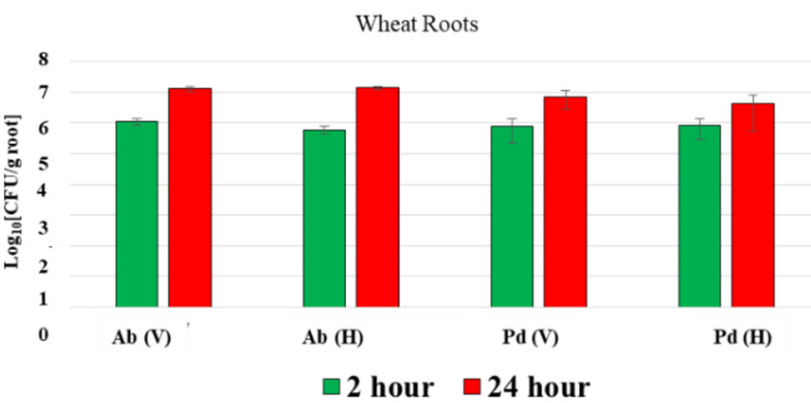

Figure 1. Root colonization ability of Azospirillum brasilense Sp7 (Ab) and Paenibacillus dendritiformis $\mathrm{T}(\mathrm{Pd})$ on roots of tomato cv. M82 (a), melon cv. Ofir (b), and wheat cv. Bar Nir (c). Seven-day-old roots were incubated for 2 or $24 \mathrm{~h}$ in bacterial suspensions with $10^{8} \mathrm{CFU} \mathrm{mL}{ }^{-1}$. After gentle washing of the roots, bacteria were detached from the roots by vortex $(\mathrm{V})$, followed by homogenization $(\mathrm{H})$, and $\mathrm{CFU} \mathrm{g} \mathrm{g}^{-1}$ root were determined by dilution plating following each one of the treatments. Data represent means and standard errors (SE) of four replicates per treatment of one experiment, out of four with similar results.

\subsection{Azospirillum brasilense Sp7 and P. dendritiformis T Promote Melon Seedling Growth in Germination Paper under Salinity Stress}

After validating the root colonization abilities of $A$. brasilense $\mathrm{Sp} 7$ and $P$. dendritiformis $\mathrm{T}$ in melon and tomato, we carried out plant-growth-promotion assays in germination papers soaked in a $50 \mathrm{mM} \mathrm{NaCl}$ solution to mimic salinity stress. This salinity concentration, which is relevant to agricultural practices using brackish water for irrigation, was enough to negatively affect the growth parameters of melon plants (Figure S2). Inoculation with both strains, separately or together, significantly promoted the growth of melon seedlings of the three tested melon cultivars, Ofir, Raymond and AN-305. In the three cultivars, significant $(p<0.05)$ increases in root weight, root length, number of lateral roots and number or lateral roots equal or longer than $2 \mathrm{~cm}$ were measured for all three bacterial treatments (each strain alone and combined inoculation) as compared to non-inoculated controls (Figure 2). For example, combined-bacterial inoculation treatments increased root weight by $47 \%, 210 \%$ and $81 \%$ and root length by $33 \%, 60$ and $25 \%$ in Ofir, Raymond and AN-305 cultivars, respectively. While no significant differences were observed between the different inoculation treatments, the combined inoculation of A. brasilense Sp7 and 
P. dendritiformis $\mathrm{T}$ consistently yielded slightly higher root parameter averages than the individual inoculations (Figure 2).

(a)

0.6

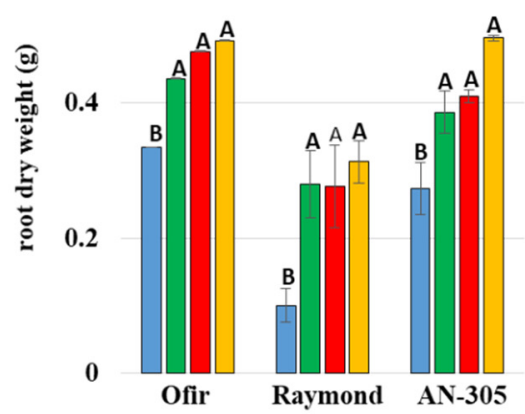

(c)

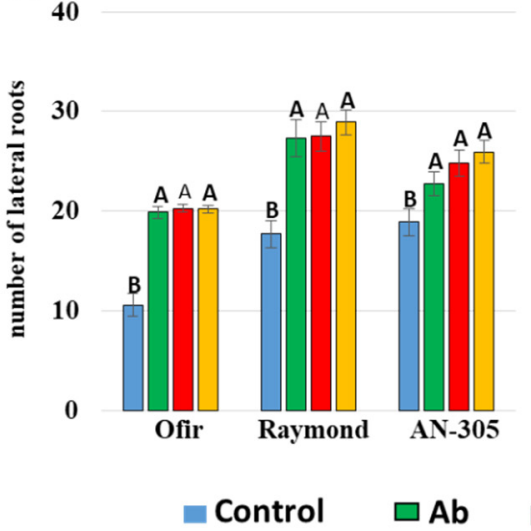

(b)

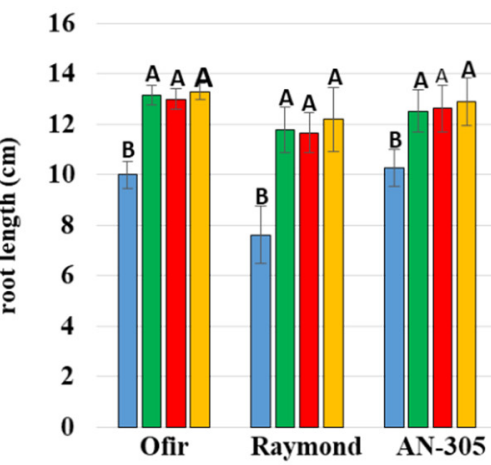

(d)

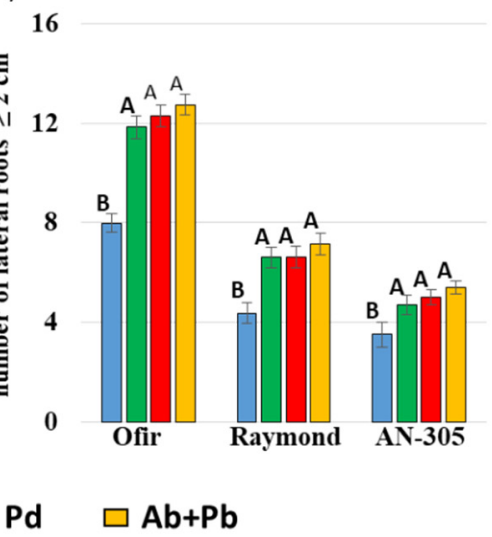

Figure 2. Growth promotion of melon seedlings (cultivars Ofir, Raymond and AN-305) induced by inoculation of Azospirillum brasilense Sp7 (Ab), Paenibacillus dendritiformis $\mathrm{T}(\mathrm{Pb})$, and their combination $(\mathrm{Ab}+\mathrm{Pb})$. Experiments were carried out in germination papers using the "cigar roll" method. Ten seeds previously soaked in the appropriate bacterial suspension were used in each roll. Growth parameters were measured after 10 days: root dry weight (a); root length (b); number of lateral roots (c); and number of lateral roots longer than $2 \mathrm{~cm}(\mathrm{~d})$. Data represent means and SE of 30 replicates (plants) per treatment from one experiment out of two with similar results. Different letters indicate significant statistical differences $(p<0.05)$ according to one way ANOVA and Tukey post hoc.

Interestingly, in contrast with the positive effects that bacterial treatment had on melon plants, no significant effects of inoculation were observed in experiments performed with tomato cv. M82 under saline stress of $50 \mathrm{mM} \mathrm{NaCl}$ (Figure S3). These results coincide with the fact that tomato plants, in contrast to melon plants, did not exhibit growth inhibition when exposed to $50 \mathrm{mM} \mathrm{NaCl}$ (Figure S2), suggesting that the plants did not experience significant stress under these conditions.

\subsection{Azospirillum brasilense Sp7 and P. dendritiformis T Promote Growth of Melon Plants under} Salinity Stress in the Greenhouse

The effects of $A$. brasilense Sp7 and P. dendritiformis T on plant-growth parameters were also tested on melon and tomato plants grown in the greenhouse under an irrigation regime with saline water. Inoculation with each of the bacterial strains separately or with a combination of both strains, significantly $(p<0.05)$ promoted the growth of the three tested melon cultivars relative to non-inoculated controls (Figure 3). In fact, combined bacterial inoculation treatments increased root dry weight by $102 \%, 96 \%$ and $78 \%$ and shoot dry weight by $57 \%, 41 \%$ and $37 \%$ in Ofir, Raymond and AN-305 cultivars, respectively. Although no significant differences were observed between single and combined 
inoculation treatment, Raymond and AN-305 plants inoculated with the combination of A. brasilense and $P$. dendritiformis consistently exhibited a trend of higher shoot and root weight averages compared to plants inoculated with each strain individually (Figure 3). In contrast to the positive effect observed with inoculated melon plants, and as similar as observed in germination paper experiments, bacterial inoculation did not promote the growth of tomato cv. M82 plants in comparison to the untreated control plants (Figure S4).

(a)

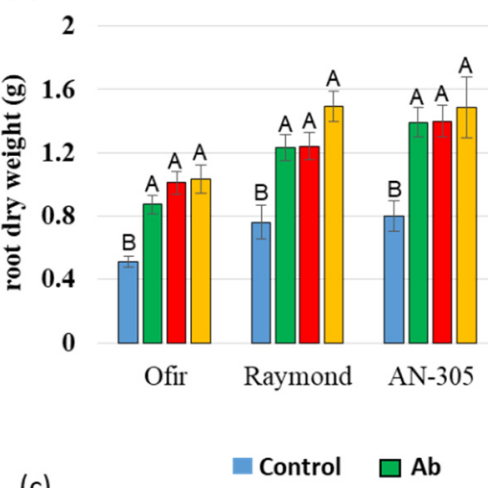

(b)

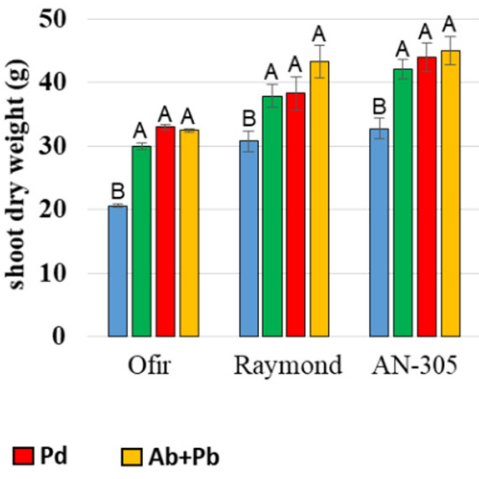

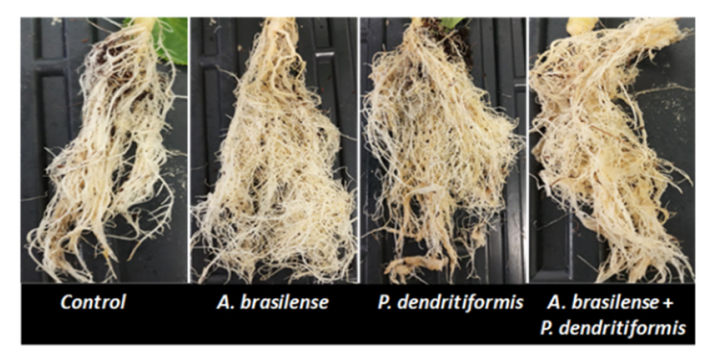

Figure 3. Growth promotion of melon plants (cultivars Ofir, Raymond and AN-305) induced by inoculation of Azospirillum brasilense Sp7 (Ab), Paenibacillus dendritiformis $\mathrm{T}(\mathrm{Pb})$, and their combination $(\mathrm{Ab}+\mathrm{Pb})$. Plants were grown in the greenhouse in $2 \mathrm{~L}$ pots filled with sand, under saline stress (irrigation solution with $\mathrm{NaCl}$ at an $\mathrm{EC}$ of $\sim 3.5 \mathrm{dS} \mathrm{m}^{-1}$ ). At 57 days after sowing, root dry weight (a) and shoot dry weight (b) were measured. (c) A representative image of AN-305 roots obtained from the different treatments. Data in graphs represent means and SE of 20 replicates per treatment from one experiment out of two with similar results. Different letters indicate significant statistical differences $(p<0.05)$ according to one way ANOVA and Tukey post hoc.

\subsection{Effects of A. brasilense Sp7 and P. dendritiformis T Inoculation on Total Antioxidant Activity}

The above results suggested that inoculation with $A$. brasilense Sp7 and P. dendritiformis $\mathrm{T}$, separately or together, alleviated the negative effect of saline stress on growth of melon plants. Several studies showed that salinity stress promotes formation of reactive oxygen species and consequent increase of total antioxidant activity in plants [58,59]. Based on this background, we compared total antioxidant activity in inoculated melon plants relative to controls. The results, presented as the percentage of radical scavenging activity, indicated that indeed, following exposure to salinity stress, roots and leaves of plants inoculated with $A$. brasilense, $P$. dendritiformis or a combination of both strains exhibited significantly $(p<0.05)$ lower antioxidant activity as compared with non-inoculated plants (Figure 4$)$. Specifically, scavenging activity measured in roots decreased from $80 \%$ in control plants to $54 \%, 61 \%$ and $65 \%$ in plants inoculated with A. brasilense Sp7, P. dendritiformis $\mathrm{T}$ and their combination, respectively. Similarly, scavenging activity in measured leaves decreased from $84 \%$ in control plants to $60 \%, 53 \%$ and $61 \%$ in plants inoculated with A. brasilense Sp7, $P$. dendritiformis $\mathrm{T}$ and their combination, respectively. 
(a)

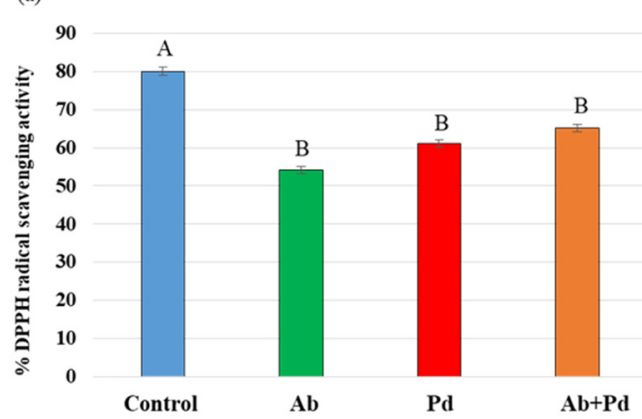

(b)

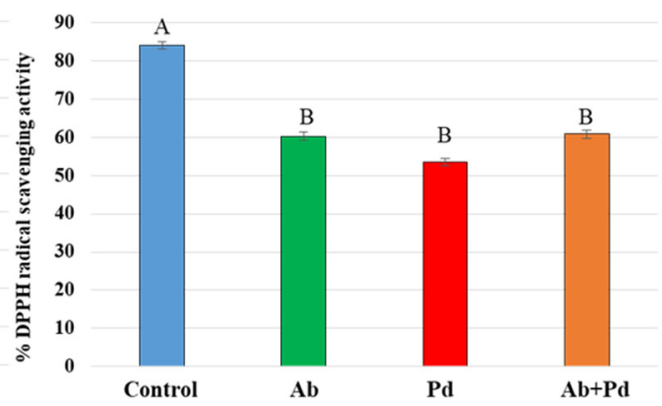

Figure 4. Effect of Azospirillum brasilense $\mathrm{Sp7}(\mathrm{Ab})$, Paenibacillus dendritiformis $\mathrm{T}(\mathrm{Pb})$ and their combination $(\mathrm{Ab}+\mathrm{Pb})$ on total antioxidant activity (DPPH radical scavenging activity) in melon plants (cultivar Ofir) grown for 45 days in the greenhouse under saline stress (irrigation solution with $\mathrm{NaCl}$ at an EC of $\sim 3.5 \mathrm{dS} \mathrm{m}^{-1}$ ). Results represent percentage of DPPH radical scavenging activity in $1 \mathrm{~g}$ of fresh root (a) or leaf tissue (b). Data are means and SE of four replicates from one experiment out of two with similar results. Different letters indicate significant statistical differences $(p<0.05)$ according to one way ANOVA and Tukey post hoc.

\subsection{Combined Inoculation with A. brasilense Sp7 and P. dendritiformis T Increased Melon Yield in} the Field under Saline Irrigation

The positive effects of A. brasilense Sp7 and P. dendritiformis T on melon plants in germination paper and greenhouse experiments under saline conditions led us to set a field experiment at Ein Tamar (Northern Arava) to assess whether inoculation with the two strains can increase fruit yield in the field under irrigation with local, saline water $\left(\sim 3.5 \mathrm{dS} \mathrm{m}^{-1}\right)$. Importantly, crop cultivation was conducted according to standard commercial practices for melon in the region, including optimized fertilization regime. Even under such optimized conditions (apart the use of saline water for irrigation, i.e., suboptimal water quality), inoculation with $P$. dendritiformis $\mathrm{T}$, as well as co-inoculation with A. brasilense Sp7 and P. dendritiformis T resulted in a significantly $(p<0.05)$ higher number of fruits (increases of $16 \%$ ) and total fruit weight (increases of $15 \%$ ) per plot as compared to non-inoculated controls (Figure 5). Plants inoculated with A. brasilense Sp7 alone showed increases of $6 \%$ and $8 \%$ in fruit number and weight, respectively, as compared to noninoculated controls; however, these differences were not statistically significant. On the other hand, the $A$. brasilense Sp7 treatment did not significantly differ in these parameters from the P. dendritiformis $\mathrm{T}$ and the co-inoculation treatments as well (Figure 5).
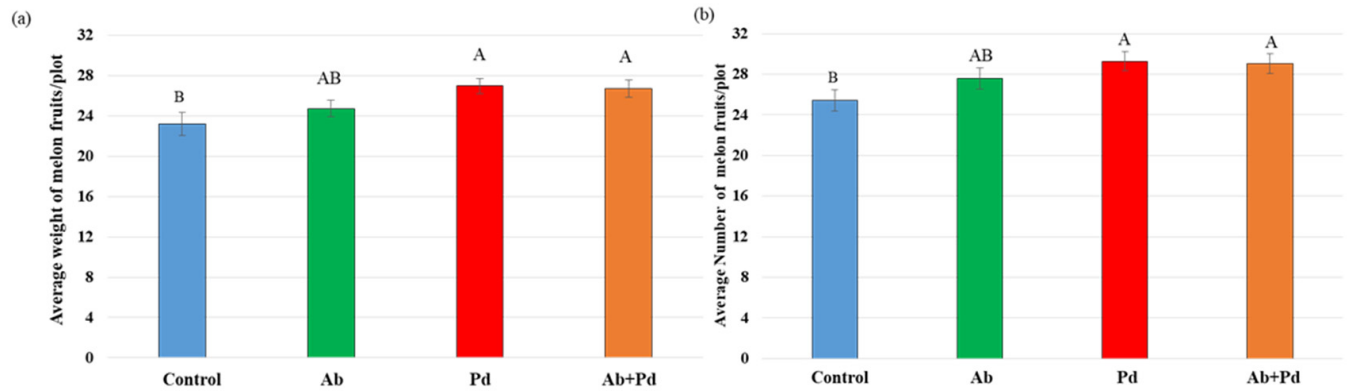

Figure 5. Effects of inoculation with Azospirillum brasilense $\mathrm{Sp} 7(\mathrm{Ab})$, Paenibacillus dendritiformis (Pd), and their combination $(\mathrm{Ab}+\mathrm{Pb})$ on yield of melon $\mathrm{cv}$. AN-305 in the field. Plants were grown at the Zohar agricultural research station at Ein Tamar, Israel for 120 days. Plants were fertilized according to commercial requirements and irrigated with saline water (EC $\sim 3.5 \mathrm{dS} \mathrm{m}^{-1}$ ). Average weight (a) and number (b) of fruits per plot were determined at the end of the experiment. Data are means and SE of 20 plots per treatment (each plot containing 10 plants). Different letters indicate significant statistical differences $(p<0.05)$ according to one way ANOVA and Tukey post hoc. 


\section{Discussion}

The identification of beneficial microbes that can ameliorate plant tolerance to abiotic stress is becoming a goal of high importance, especially in light of the prevailing climate changes that lead to irregular precipitation, increased temperature, and soil salinization worldwide. In the present study, we examined the effect of two beneficial bacterial strains, Azospirillum brasilense Sp7 and Paenibacillus dendritiformis T, on plant growth parameters, focusing on their potential to enhance the plant's capacity to tolerate salinity stress. A crucial requirement of PGPR inoculants is to efficiently colonize plant roots. We found that $A$. brasilense $\mathrm{Sp} 7$ and P. dendritiformis $\mathrm{T}$ can colonize roots of melon and tomato plants at levels similar to those measured in wheat (Figure 1), a plant whose roots are efficiently colonized by A. brasilense [52]. Our results showed that both A. brasilense Sp7 and P. dendritiformis $\mathrm{T}$, separately or together, are able to alleviate salinity stress in melon plants, specifically affecting the plant root architecture and biomass. Significant increase in the number of lateral roots, length and biomass was observed in melon seedlings inoculated with both strains grown on germination paper under saline stress (Figure 2). This effect was further noticed in greenhouse experiments where root and shoot weights of inoculated plants were much higher than non-inoculated plants (Figure 3), and corroborated in the field under standard agricultural practices, with increases in crop yields (Figure 5).

Salinity reduces water availability to plants by decreasing the osmotic potential of the soil solution [60]. Since roots provide the primary mechanism that plants use to absorb water and nutrients, increased surface area could positively affect water uptake and decrease the stress experienced by plants irrigated with saline water [61,62]. In this regard, the decreased antioxidant activity exhibited by the plants inoculated with A. brasilense and $P$. dendritiformis (Figure 4) coincides with the bigger root biomass measured in these plants (Figures 2 and 3), suggesting that inoculated plants experienced reduced stress compared to controls. With that said, future experiments comparing antioxidant activity in stressed and non-stressed plants, as well as additional antioxidant activity measurements examining enzymatic and non-enzymatic pathways, are required in order to determine the contribution of $A$. brasilense $\mathrm{Sp} 7$ and $P$. dendritiformis $\mathrm{T}$ to detoxification of reactive oxygen species in plants grown under saline conditions.

In contrast with the positive effects induced by A. brasilense Sp7 and P. dendritiformis $\mathrm{T}$ in melon plants, we were not able to detect plant-growth-promotion effects by these bacteria on tomato plants. These results somehow contradict previous findings by Hadas and Okon [40] who showed that A. brasilense strain Cd positively affected morphology and growth parameters of tomato seedling roots. While these discrepancies could be due to differences in experimental set-up and bacterial strains, it is important to stress that according to that study, the positive effects of $A$. brasilense on tomato were dosedependent [40]. In addition, Mangmang et al. [41] reported that some $A$. brasilense strains, including strain Sp7, were able to enhance root and shoot growth of tomato seedlings; however, this study focused on the early stage of seedling emergence.

Co-inoculation of $P$. dendritiformis $\mathrm{T}$ and $A$. brasilense $\mathrm{Sp} 7$ on agar plates, as well as FISH analyses performed on inoculated plants grown in sand (Figure S1), suggested that these two strains are compatible and could be used as a combined inoculum in the field. Enhanced growth of melon plants inoculated with P. dendritiformis $\mathrm{T}$ and A. brasilense Sp7 compared to control plants was consistent throughout the experiments carried out in growth chambers, greenhouse and in the field. Although combined inoculation of A. brasilense Sp7 and P. dendritiformis T consistently yielded slightly higher root parameter averages than the individual inoculations, the combined inoculum did not show a statistically significant additive effect. Paenibacillus dendritiformis and A. brasilense belong to very different bacterial linages, probably employing different modes of action to withstand stress, promote plant growth, and interact with the plant host and the rhizosphere microbial population. Although these premises were not confirmed, we may posit that such a combination may lead to a variety of responses to different environmental conditions, possibly complementing one another and covering a vast range of environmental and agricultural 
(including crops) scenarios. Finding effective combinations of PGPRs as presented here, which do not antagonize one another and together can alleviate abiotic stresses for field crops, is of high importance. This importance is intensified in light of the negative effects climate changes impose on agriculture productivity and considering the increasing food demand of the growing world's population.

\section{Patents}

Provisional patent application No. 63/267,340 has been submitted.

Supplementary Materials: The following supporting information can be downloaded at: https: / / www.mdpi.com/article/10.3390/agronomy12020408/s1, Figure S1: Assessing compatibility of Azospirillum brasilense Sp7 and Paenibacillus dendritiformis $\mathrm{T}$ for co-inoculation experiments. Figure S2: Assessment of tolerance to saline irrigation of melon cv. Ofir and tomato cv. M82 plants. Figure S3: Growth of tomato (cv. M82) seedlings in response to inoculation with Azospirillum brasilense $\mathrm{Sp} 7(\mathrm{Ab})$, Paenibacillus dendritiformis $\mathrm{T}(\mathrm{Pb})$, and their combination $(\mathrm{Ab}+\mathrm{Pb})$. Figure S4: Growth of tomato (cv. M82) plants in response to inoculation with Azospirillum brasilense Sp7 (Ab), Paenibacillus dendritiformis $\mathrm{T}(\mathrm{Pb})$, and their combination $(\mathrm{Ab}+\mathrm{Pb})$.

Author Contributions: Conceptualization, V.G., S.B., E.J. and Y.H.; methodology, V.G., S.B., E.J. and Y.H.; investigation, V.G., S.B., E.J. and Y.H.; writing-original draft preparation, V.G. and Y.H.; writing-review and editing, S.B., E.J. and Y.H.; supervision, S.B., E.J. and Y.H.; funding acquisition, S.B., E.J. and Y.H. All authors have read and agreed to the published version of the manuscript.

Funding: This research was partially supported by grants from the ICA in Israel Foundation and from the Israel Ministry of Agriculture and Rural Development (Eugene Kandel Knowledge centers) as part of the Root of the Matter-The root zone knowledge center for leveraging modern agriculture.

Institutional Review Board Statement: Not applicable.

Informed Consent Statement: Not applicable.

Data Availability Statement: Data is available within the article and supplementary information.

Acknowledgments: We thank Shimon Pivonia from the Zohar agricultural station for the set-up of the field experiment; Menachem Moshelion for helping with greenhouse experiments; Francisco Pérez-Montaño, Irene Jiménez-Guerrero and Daniel Youdkes for their help in the field experiment; and Dafna Tamir-Ariel and Neta Rotem for their technical support.

Conflicts of Interest: The authors declare no conflict of interest.

\section{References}

1. Munns, R.; Gilliham, M. Salinity tolerance of crops-what is the cost? New Phytol. 2015, 208, 668-673. [CrossRef]

2. Stavridou, E.; Webster, R.J.; Robson, P.R.H. The Effects of moderate and severe salinity on composition and physiology in the biomass crop. Plants 2020, 9, 1266. [CrossRef]

3. Rengasamy, P. Soil processes affecting crop production in salt-affected soils. Funct. Plant Biol. 2010, 37, 613-620. [CrossRef]

4. Gupta, R.K.; Abrol, I.P.; Finkl, C.W.; Kirkham, M.B.; Arbestain, M.C.; Macías, F.; Chesworth, W.; Germida, J.J.; Loeppert, R.H.; Cook, M.G.; et al. Soil Salinity and Salinization. In Encyclopedia of Soil Science; Chesworth, W., Ed.; Springer: Dordrecht, The Netherlands, 2008; pp. 699-704. [CrossRef]

5. Rengasamy, P. World salinization with emphasis on Australia. J. Exp. Bot. 2006, 57, 1017-1023. [CrossRef]

6. Chen, Z.; Pottosin, I.I.; Cuin, T.A.; Fuglsang, A.T.; Tester, M.; Jha, D.; Zepeda-Jazo, I.; Zhou, M.; Palmgren, M.G.; Newman, I.A.; et al. Root plasma membrane transporters controlling $\mathrm{K}+/ \mathrm{Na}+$ homeostasis in salt-stressed barley. Plant Physiol. 2007, 145, 1714-1725. [CrossRef]

7. Demidchik, V.; Maathuis, F.J. Physiological roles of nonselective cation channels in plants: From salt stress to signalling and development. New Phytol. 2007, 175, 387-404. [CrossRef]

8. Pandolfi, C.; Pottosin, I.; Cuin, T.; Mancuso, S.; Shabala, S. Specificity of polyamine effects on NaCl-induced ion flux kinetics and salt stress amelioration in plants. Plant Cell Physiol. 2010, 51, 422-434. [CrossRef]

9. Canfora, L.; Bacci, G.; Pinzari, F.; Lo Papa, G.; Dazzi, C.; Benedetti, A. Salinity and bacterial diversity: To what extent does the concentration of salt affect the bacterial community in a saline soil? PLoS ONE 2014, 9, e106662. [CrossRef]

10. Chandra, P.; Dhuli, P.; Verma, P.; Singh, A.; Choudhary, M.; Prajapat, K.; Rai, A.K.; Yadav, R.K. Culturable microbial diversity in the rhizosphere of different biotypes under variable salinity. Trop. Ecol. 2020, 61, 291-300. [CrossRef] 
11. Matsuguchi, T.; Sakai, M. Influence of soil-salinity on the population and composition of fluorecent pseudomonads in plant rhizosphere. Soil Sci. Plant Nutr. 1995, 41, 497-504. [CrossRef]

12. Food and Agriculture Organization (FAO) of the United Nations; ITPS. Status of the World's Soil Resources (SWSR)-Main Report; FAO: Rome, Italy, 2015.

13. Qadir, M.; Ghafoor, A.; Murtaza, G. Amelioration strategies for saline soils: A review. Land Degrad. Dev. 2000, 11, 501-521. [CrossRef]

14. Machado, R.M.A.; Serralheiro, R.P. Soil Salinity: Effect on vegetable crop growth. management practices to prevent and mitigate soil salinization. Horticulturae 2017, 3, 30. [CrossRef]

15. Vacheron, J.; Desbrosses, G.; Bouffaud, M.L.; Touraine, B.; Moënne-Loccoz, Y.; Muller, D.; Legendre, L.; Wisniewski-Dyé, F.; Prigent-Combaret, C. Plant growth-promoting rhizobacteria and root system functioning. Front. Plant Sci. 2013, 4, 356. [CrossRef]

16. Adesemoye, A.O.; Torbert, H.A.; Kloepper, J.W. Plant growth-promoting rhizobacteria allow reduced application rates of chemical fertilizers. Microb. Ecol. 2009, 58, 921-992. [CrossRef]

17. Yang, J.; Kloepper, J.W.; Ryu, C.M. Rhizosphere bacteria help plants tolerate abiotic stress. Trends Plant Sci. 2009, 14, 1-4. [CrossRef]

18. Ilangumaran, G.; Smith, D.L. Plant growth promoting rhizobacteria in amelioration of salinity stress: A systems biology perspective. Front. Plant Sci. 2017, 8, 1768. [CrossRef]

19. Bloemberg, G.V.; Lugtenberg, B.J. Molecular basis of plant growth promotion and biocontrol by rhizobacteria. Curr. Opin. Plant Biol. 2001, 4, 343-350. [CrossRef]

20. Lugtenberg, B.; Kamilova, F. Plant-growth-promoting rhizobacteria. Ann. Rev. Microbiol. 2009, 63, 541-556. Available online: https:/ / www.annualreviews.org/doi/full/10.1146/annurev.micro.62.081307.162918 (accessed on 2 January 2022). [CrossRef]

21. Kloepper, J.W.; Leong, J.; Teintze, M.; Schroth, M.N. Enhanced plant growth by siderophores produced by plant growth-promoting rhizobacteria. Nature 1980, 286, 885-886. [CrossRef]

22. Pal, K.K.; Tilak, K.V.; Saxena, A.K.; Dey, R.; Singh, C.S. Antifungal characteristics of a fluorescent Pseudomonas strain involved in the biological control of Rhizoctonia solani. Microbiol. Res. 2000, 155, 233-242. [CrossRef]

23. Raza, W.; Yang, W.; Shen, Q.R. Paenibacillus polymyxa: Antibiotics, hydrolytic enzymes and hazard assessment. J. Plant Pathol. 2008, 90, 419-430.

24. Ryu, C.M.; Farag, M.A.; Hu, C.H.; Reddy, M.S.; Wei, H.X.; Pare, P.W.; Kloepper, J.W. Bacterial volatiles promote growth in Arabidopsis. Proc. Natl. Acad. Sci. USA 2003, 100, 4927-4932. [CrossRef]

25. Jjemba, P.K.; Alexander, M. Possible determinants of rhizosphere competence of bacteria. Soil Biol. Biochem. 1999, 31, 623-632. [CrossRef]

26. Okon, Y.; Labandera-Gonzales, C.; Lage, M.; Lage, P. Agronomic applications of Azospirillum and other PGPR. In Biological Nitrogen Fixation; de Bruijn, F.J., Ed.; Wiley: Hoboken, NJ, USA, 2015; pp. 925-936.

27. Burdman, S.; Kigel, J.; Okon, Y. Effects of Azospirillum brasilense on nodulation and growth of common bean (Phaseolus vulgaris L.). Soil Biol. Biochem. 1997, 29, 923-929. [CrossRef]

28. Volpin, H.; Burdman, S.; CastroSowinski, S.; Kapulnik, Y.; Okon, Y. Inoculation with Azospirillum increased exudation of rhizobial nod-gene inducers by alfalfa roots. Mol. Plant-Microbe Interact. 1996, 9, 388-394. [CrossRef]

29. Dobbelaere, S.; Croonenborghs, A.; Thys, A.; Ptacek, D.; Vanderleyden, J.; Dutto, P.; Labandera-Gonzalez, C.; Caballero-Mellado, J.; Aguirre, J.F.; Kapulnik, Y.; et al. Responses of agronomically important crops to inoculation with Azospirillum. Aust. J. Plant Physiol. 2001, 28, 871-879. [CrossRef]

30. Barbosa, J.Z.; Hungria, M.; Sena, J.V.D.; Poggere, G.; dos Reis, A.R.; Correa, R.S. Meta-analysis reveals benefits of co-inoculation of soybean with Azospirillum brasilense and Bradyrhizobium spp. in Brazil. Appl. Soil Ecol. 2021, 163. [CrossRef]

31. Masciarelli, O.; Llanes, A.; Luna, V. A new PGPR co-inoculated with Bradyrhizobium japonicum enhances soybean nodulation. Microbiol. Res. 2014, 169, 609-615. [CrossRef] [PubMed]

32. Ju, W.; Liu, L.; Jin, X.; Duan, C.; Cui, Y.; Wang, J.; Ma, D.; Zhao, W.; Wang, Y.; Fang, L. Co-inoculation effect of plant-growthpromoting rhizobacteria and rhizobium on EDDS assisted phytoremediation of $\mathrm{Cu}$ contaminated soils. Chemosphere 2020, 254, 126724. [CrossRef]

33. Grady, E.N.; MacDonald, J.; Liu, L.; Richman, A.; Yuan, Z.C. Current knowledge and perspectives of Paenibacillus: A review. Microb.Cell Fact. 2016, 15. [CrossRef]

34. Fibach-Paldi, S.; Burdman, S.; Okon, Y. Key physiological properties contributing to rhizosphere adaptation and plant growth promotion abilities of Azospirillum brasilense. FEMS Microbiol. Lett. 2012, 326, 99-108. [CrossRef] [PubMed]

35. Helman, Y.; Burdman, S.; Okon, Y. Plant growth promotion by rhizosphere bacteria through direct reffects. In Beneficial Microorganisms in Multicellular Life Forms; Rosenberg, E., Gophna, U., Eds.; Springer: Berlin/Heidelberg, Germany, 2011; pp. 89-103. [CrossRef]

36. Burdman, S.; Jurkevitch, E.; Okon, Y. Recent Advances in the Use of Plant Growth Promoting Rhizobacteria (PGPR) in Agriculture. In Microbial Interactions in Agriculture and Forestry (Volume II); Subba Rao, N.S., Dommergues, Y.R., Eds.; Science Publishers: Enfield, NH, USA, 2000; pp. 229-250.

37. Li, J.Y.; Gao, T.T.; Wang, Q. Comparative and functional analyses of two sequenced Paenibacillus polymyxa genomes provides insights into their potential genes related to plant growth-promoting features and biocontrol mechanisms. Front. Genet. 2020, 11, 1374. [CrossRef]

38. Brito, L.F.; Lopez, M.G.; Straube, L.; Passaglia, L.M.P.; Wendischl, V.F. Inorganic phosphate solubilization by rhizosphere bacterium Paenibacillus sonchi: Gene expression and physiological functions. Front. Microbiol. 2020, 11. [CrossRef] [PubMed] 
39. Spaepen, S.; Vanderleyden, J.; Okon, Y. Plant growth-promoting actions of rhizobacteria. Adv. Bot. Res. 2009, 51, 283-320. [CrossRef]

40. Hadas, R.; Okon, Y. Effect of Azospirillum brasilense inoculation on root morphology and respiration in tomato seedlings. Biol. Fert. Soils 1987, 5, 241-247. [CrossRef]

41. Mangmang, J.S.; Deaker, R.; Rogers, G. Early seedling growth response of lettuce, tomato and cucumber to Azospirillum brasilense inoculated by soaking and drenching. Hortic. Sci. 2015, 42, 37-46. [CrossRef]

42. Sirota-Madi, A.; Olender, T.; Helman, Y.; Brainis, I.; Finkelshtein, A.; Roth, D.; Hagai, E.; Leshkowitz, D.; Brodsky, L.; Galatenko, V.; et al. Genome sequence of the pattern-forming social bacterium Paenibacillus dendritiformis C454 chiral morphotype. J. Bacteriol. 2012, 194, 2127-2128. [CrossRef]

43. Lapidot, D.; Dror, R.; Vered, E.; Mishli, O.; Levy, D.; Helman, Y. Disease protection and growth promotion of potatoes (Solanum tuberosum L.) by Paenibacillus dendritiformis. Plant Pathol. 2014, 64, 545-551. [CrossRef]

44. Radhakrishnan, R.; Ajithkumar, P.; Arun, M.; Sathasivam, R.; Sandhya, S.; Choi, J.; Park, S.U. An endophyte Paenibacillus dendritiformis strain APL3 promotes Amaranthus polygonoides L. sprout growth and their extract inhibits food-borne pathogens. Plant Sci. Today 2021, 8, 941-947. [CrossRef]

45. Yadav, M.; Dubey, M.K.; Upadhyay, R.S. Systemic resistance in chilli pepper against anthracnose (caused by Colletotrichum truncatum) induced by Trichoderma harzianum, Trichoderma asperellum and Paenibacillus dendritiformis. J. Fungi 2021, 7, 307. [CrossRef]

46. Tarrand, J.J.; Krieg, N.R.; Döbereiner, J. A taxonomic study of the Spirillum lipoferum group, with descriptions of a new genus, Azospirillum gen. nov. and two species, Azospirillum lipoferum (Beijerinck) comb. nov. and Azospirillum brasilense sp. nov. Can. J. Microbiol. 1978, 24, 967-980. [CrossRef]

47. Tcherpakov, M.; Ben-Jacob, E.; Gutnick, D.L. Paenibacillus dendritiformis sp. nov., proposal for a new pattern-forming species and its localization within a phylogenetic cluster. Int. J. Syst. Bacteriol. 1999, 49, 239-246. [CrossRef]

48. Simon, R.; Priefer, U.; Puhler, A. A broad host range mobilization system for in vivo genetic engineering transposon mutagenesis in Gram negative bacteria. Bio-Technology 1983, 1, 784-791. [CrossRef]

49. Bai, C.H.; Liang, Y.L.; Hawkesford, M.J. Identification of QTLs associated with seedling root traits and their correlation with plant height in wheat. J. Exp. Bot. 2013, 64, 1745-1753. [CrossRef]

50. Zhou, Y.; Tang, N.; Huang, L.; Zhao, Y.; Tang, X.; Wang, K. Effects of salt stress on plant growth, antioxidant capacity, glandular trichome density, and volatile exudates of Schizonepeta tenuifolia Briq. Int. J. Mol. Sci. 2018, 19, 252. [CrossRef]

51. Kumar, Y.; Westram, R.; Behrens, S.; Fuchs, B.; Glockner, F.O.; Amann, R.; Meier, H.; Ludwig, W. Graphical representation of ribosomal RNA probe accessibility data using ARB software package. BMC Bioinform. 2005, 6, 61. [CrossRef]

52. Michiels, K.W.; Croes, C.L.; Vanderleyden, J. Two different modes of attachment of Azospirillum brasilense Sp7 to wheat roots. J. Gen. Microbiol. 1991, 137, 2241-2246. [CrossRef]

53. Burdman, S.; Okon, Y.; Jurkevitch, E. Surface characteristics of Azospirillum brasilense in relation to cell aggregation and attachment to plant roots. Crit. Rev. Microbiol. 2000, 26, 91-110. [CrossRef]

54. Rodríguez-Navarro, D.N.; Dardanelli, M.S.; Ruíz-Saínz, J.E. Attachment of bacteria to the roots of higher plants. FEMS Microbiol. Lett. 2007, 272, 127-136. [CrossRef]

55. Wheatley, R.M.; Poole, P.S. Mechanisms of bacterial attachment to roots. FEMS Microbiol. Rev. 2018, 42, 448-461. [CrossRef]

56. Al-Amoudi, S.; Essack, M.; Simões, M.F.; Bougouffa, S.; Soloviev, I.; Archer, J.A.; Lafi, F.F.; Bajic, V.B. Bioprospecting red sea coastal ecosystems for culturable microorganisms and their antimicrobial potential. Mar. Drugs 2016, 14, 165. [CrossRef]

57. Jangra, M.; Randhawa, H.K.; Kaur, M.; Srivastava, A.; Maurya, N.; Patil, P.P.; Jaswal, P.; Arora, A.; Patil, P.B.; Raje, M.; et al. Purification, Characterization and in vitro evaluation of polymyxin A from Paenibacillus dendritiformis: An underexplored member of the polymyxin family. Front. Microbiol. 2018, 9, 2864. [CrossRef]

58. Miranda, D.; Fischer, G.; Mewis, I.; Rohn, S.; Ulrichs, C. Salinity effects on proline accumulation and total antioxidant activity in leaves of the cape gooseberry (Physalis peruviana L.). J. Appl. Bot. Food Qual. 2014, 87, 67-73. [CrossRef]

59. Dat, J.; Vandenabeele, S.; Vranova, E.; van Montagu, M.; Inze, D.; van Breusegem, F. Dual action of the active oxygen species during plant stress responses. Cell. Mol. Life Sci. 2000, 57, 779-795. [CrossRef] [PubMed]

60. Sheldon, A.R.; Dalal, R.C.; Kirchhof, G.; Kopittke, P.M.; Menzies, N.W. The effect of salinity on plant-available water. Plant Soil 2017, 418, 477-491. [CrossRef]

61. Arif, M.R.; Islam, M.T.; Robin, A.H.K. Salinity stress alters root morphology and root hair traits in Brassica napus. Plants 2019, 8, 192. [CrossRef]

62. Rewald, B.; Raveh, E.; Gendler, T.; Ephrath, J.E.; Rachmilevitch, S. Phenotypic plasticity and water flux rates of Citrus root orders under salinity. J. Exp. Bot. 2012, 63, 2717-2727. [CrossRef] 